\title{
The systematic energy management of transport facilities for a holistic reduction of greenhouse emissions
}

\author{
K. Rommelspacher, W. J. Conradie \& C. J. Fourie \\ Department of Industrial Engineering, \\ Stellenbosch University, South Africa
}

\begin{abstract}
The management of energy generally focuses on point-of-use consumption, specifically on those of the actual vehicles used. In order to reduce the total system consumptions and to take energy management into the future, energy supply and consumption needs to be investigated holistically on a systematic level. Energy consumption is generally directly proportional to greenhouse emissions. This is particularly relevant to South Africa where the majority of all energy consumed is fossil fuel-based. Included in this is the electricity used by the various facilities that are used by the rail industry. The feasibility of reducing fossil fuel-based energy consumption, at rail facilities forms the basis of this article. In order to reduce the fossil fuel-based energy consumption either the amount of energy consumed, or the type of energy consumed or both need to change. Financial feasibility of any such shift is a key component to encourage industry to adopt these recommendations. In order to validate the financial feasibility of the recommendations a case study that was performed at the Salt River maintenance facilities of Metrorail, Cape Town, South Africa, is discussed.
\end{abstract}

Keywords: energy management, point-of-use consumption, total system consumption, energy consumption, energy shift.

\section{Introduction}

The reduction of greenhouse gases has been central to the rail industry for many years. The focus on reducing the emissions and carbon footprint at the point of use has resulted in significant technological developments and progress in the past years. However, Point of Use Emissions (PUE) are only one aspect of the 
emissions of the entire transport system. There are various factors that contribute to Total System Emissions (TSE). TSE can be grouped into two main categories; they are the full life cycle emissions of the vehicles used and the full life cycle emissions of the entire rail infrastructure. One element of the full life cycle emissions of the infrastructure are the operational emissions of rail facilities.

Most rail facilities in South Africa use electricity as their main source of energy, thus this is the primary starting point for managing a facilities emissions. There are two methods to reduce the energy consumption based emissions of rail facilities. The first is to reduce the amount of energy consumed and the second is to change the source or type of energy to one with lower emissions.

In South Africa electricity is generally supplied directly or indirectly by Eskom. Unfortunately at least $90 \%$ of the electricity generated by Eskom is produced by fossil fuel consumption. It is thus of particular importance for TSE reduction to manage the energy usage of rail facilities.

From an emissions point of view the need and the path are clear. However the perceived economic infeasibility of such undertakings has been the greatest hindrance to wide scale changes.

The aim of this paper is to investigate the economic feasibility of implementing the above mentioned energy management methods that will result in a reduction of the TSE of the rail industry.

\section{Literature}

In order to develop and evaluate widely applicable TSE reduction principles for rail facilities, focus is given to areas that are common to most rail facilities. These facilities include but are not limited to: Large and small stations, Maintenance facilities, assembly facilities/plants, Shunting yards, Offices as well as facilities of suppliers to the rail industry. Areas of commonality include: the source of energy, electrical lighting, water heating, HVAC (heating, ventilation and air conditioning), and computers and office equipment. For the purposes of this Case Study only the source of energy and electrical lighting aspects will be discussed in greater detail in the literature.

As stated in Section 1, about $90 \%$ of the power generated in South Africa by Eskom comes fossil fuels. For 2012 Eskom published the emissions/kWh as per Table $1[1]$.

Table 1: Emissions breakdown for South African electricity production.

\begin{tabular}{|l|c|l|}
\hline & Electricity Generated & Unit \\
\hline Particulate emissions & 0.31 & gram per $\mathrm{kWh}$ \\
\hline CO $_{2}$ emissions & 0.99 & kilogram per $\mathrm{kWh}$ \\
\hline SO $_{\mathbf{x}}$ emissions & 7.93 & gram per $\mathrm{kWh}$ \\
\hline NO $_{\mathbf{x}}$ emissions & 4.19 & gram per $\mathrm{kWh}$ \\
\hline
\end{tabular}




\subsection{Lighting}

Apart from simply switching lights off when not in use, effectively managing lighting systems is one of the easiest and most cost-effective ways to reduce electricity bills [2]. By upgrading lighting systems with efficient light bulbs, fixtures, and controls, the visual working environment can be improved.

When selecting the appropriate lighting system, factors such as light requirement levels and maintenance should be considered.

\subsubsection{Possible improvements for indoor and outdoor lighting}

The following steps can significantly reduce light energy consumption. It is highly recommended that any rail facility utilize these steps:

- Regularly investigate and adopt increasingly energy efficient lamps.

- De-lamp where appropriate.

- Plan and execute a comprehensive lighting maintenance program.

- Group lighting into logical zones.

- Make use of an automatic lighting control system.

\subsection{Solar energy generation}

Solar energy generation is growing at a fast rate $-25 \%$ per year [3]. Costs of photovoltaic (PV) solar panels are dropping globally due to a growing worldwide demand, improved manufacturing processes and technology [4].

Even with all these improvements and advancements the viability of using solar panels needs to be carefully considered. These considerations are discussed below.

\subsubsection{Inspection site analysis}

The most important factor to when investigating solar energy is the sun, specifically how much sunshine is available at a specific site. The annual 24-hour solar radiation average (sunshine hours) that a site experiences needs to be determined. Many countries have set up solar maps to aid industry. If no solar maps are available radiation hours need to be captured for a specific site. Based on the solar radiation levels of its cities, it is evident that South Africa is ideally located to implement solar energy initiatives [5].

The site inspection should not be limited to establishing the solar radiation suitability, but should also include the following considerations:

- Shading analysis, orientation of solar arrays, and overview of current electrical systems to integrate with PV system.

- Visual inspection of structures, roof conditions.

\subsubsection{Advantages of using solar systems}

Some advantages of using a solar system include [3]:

- Very safe, quiet, and durable generation of energy.

- Minimal carbon emissions.

- Companies can save on financially in the long run, once initial costs have been recovered. 
- Lower vulnerability to increasing energy prices from utility suppliers.

- It can improve a company's image.

- Long operational use of roughly 30 to 40 years.

- Maintenance costs are very low.

\subsubsection{Drawbacks of using solar systems}

A few drawbacks associated with using solar panels are [3]:

- High initial costs.

- Solar energy production is not constant (dependent on daylight hours).

- Solar inefficiency, which currently converts a maximum of $22 \%$ of the sun's energy into electrical energy. This means a high number of panels are required to produce acceptable amounts of electricity.

\section{Case study}

For the purpose of the Case Study the Salt River Metrorail maintenance depot in Cape Town was selected.

The financial implication of any emission reduction initiative would need to be evaluated based on its impact on the monthly energy rates.

The monthly invoice consists of two cost components, the consumption charge as well as the availability charge.

$$
\text { Total Monthly Cost }=k W h \times \frac{\text { cost }}{k W h}+k V A \text { peak } \times \frac{\text { cost }}{k V A}
$$

Based on the monthly energy consumption Invoices that PRASA receives from the Cape Town Municipality the monthly energy demand and cost of the facility was established [6].

For the purposes of this investigation it was decided that the scope of the case study would be limited to one example of reducing the energy consumption and one example of changing the energy source, both resulting in a decrease in emissions.

The facility was visited and various energy consumers were investigated as well as the potential for changing the energy source. Based on this investigation lighting was selected as the example for reducing energy consumption and the installation of solar panels as a potential change in energy source.

For any potential energy reduction initiative the following steps can be followed:

1. Conduct and AS-IS analysis of the equipment/sub-system/system.

2. Evaluate the contributions to the total energy consumption and prioritise.

3. Determine ideal performance requirements of the priority areas.

4. Table 2 Energy consumption and cost breakdown at Salt River depot.

5. Investigate possible alternatives for the following aspects:

a. Energy reduction potential.

b. Financial feasibility.

6. Make recommendations. 
Table 2: Energy consumption and cost breakdown at Salt River depot.

\begin{tabular}{|c|c|c|c|}
\hline & Consumption & Cost/unit & Cost \\
\hline Peak demand (kVA): & 695 & 231.99 & R 161110 \\
\hline Monthly consumption (kWh): & 314490 & 0.5039 & R 158472 \\
\hline & \multicolumn{2}{|c|}{ Monthly energy cost: } & R 319582 \\
\hline
\end{tabular}

\subsection{Lighting Initiatives}

The lights currently in use in the primary maintenance building are fluorescent tubes. Fluorescent tubes are mainly used in commercial buildings, due to its long light-emitting tubes, which cover larger areas.

The number of lights were then counted. The energy consumption of these lights is summarized in Table 3. Due to safety and security reasons the lights are operational 24 hours per day, 7 days a week. The lights therefore consume base power and any saving would reduce the amount of energy consumed as well as the peak energy demand costs.

For the calculation of the total power being consumed by lighting per month, 30 days was taken as the average number of days. Further investigation was conducted to determine any other areas which might result in significant potential energy savings. It was established that other contributors either had little impact on the overall energy usage, such as office lighting and computing equipment (both less than $1 \%$ ), or that most maintenance equipment in use was specialised for the type of trains being operated by Metrorail and could not be exchanged until new trains are acquired. The maintenance buildings lighting consumption, of $101,952 \mathrm{kWh}$, is $32.4 \%$ of the total monthly depot usage. It was thus deemed sufficient to focus only on the lighting for the purpose of this case study.

An assessment was also performed to establish employee lighting needs. These needs depend on the tasks being performed in the building: maintenance, part repairs, removals, and inspection. Based on these tasks the lighting level should be sufficient for applications of fine detail.

Table 3: Energy consumption by facility lighting group.

\begin{tabular}{|l|c|c|c|c|}
\hline Location & $\begin{array}{c}\text { Number } \\
\text { of lights }\end{array}$ & $\begin{array}{l}\text { Power Rate } \\
\text { (Watt) }\end{array}$ & $\begin{array}{l}\text { Usage } \\
\text { per day }\end{array}$ & $\begin{array}{l}\text { Total monthly usage, at 30 } \\
\text { days per month (kWh) }\end{array}$ \\
\hline $\begin{array}{l}\text { Overhead } \\
\text { Lighting }\end{array}$ & 960 & 80 & 24 & 55296 \\
\hline $\begin{array}{l}\text { Subterranean } \\
\text { Lighting }\end{array}$ & 1800 & 36 & 24 & 46656 \\
\hline \multicolumn{4}{|c|}{ Total Power consumption per month: } & $\mathbf{1 0 1 9 5 2 ~ k W h}$ \\
\hline
\end{tabular}


Based on the South African Occupational Health and Safety Act 1993 the minimum lux for fine and detailed work is 500 lux [7]. The recordings for various areas were taken and compared to the recommended levels, as shown in Figure 1. From the figure it can be seen that the minimum light level is exceeded in all areas in some cases significantly so.

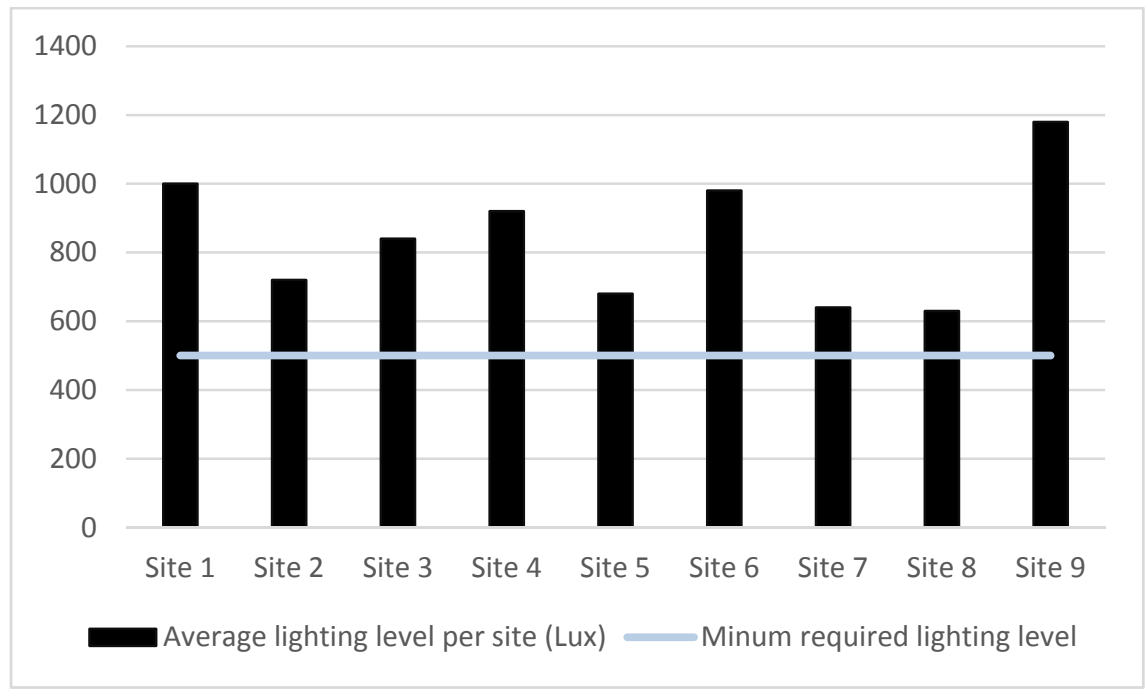

Figure 1: Salt River facility light level recordings.

\subsubsection{Alternative light sources}

Alternatives light sources should be compared on the basis of energy saving and life cycle costing, in order to establish a long term cost comparison.

Lighting alternatives were compared according to specification as well as potential cost savings and emissions reductions, as per Table 4.

In order to establish the life cycle costs a net present worth analysis was conducted. The time frame for the calculation was taken as twice the time frame of the longest expected life. Equation (1) was used for the calculation:

$$
P=- \text { Initial } \operatorname{cost}(s)+(A \times n)-\left(\frac{n}{l} \times C_{r}\right)
$$

where $P=$ present worth

$A=$ total electrical cost saving per year as per type

$n=2 \times$ maximum expected operational life (in years)

$l=$ specific expected operational life (in years)

$C_{r}=$ replacement cost of light fitting

The results of the calculation for each of the various types of light fittings is summarised in the last rows of Table 4. 


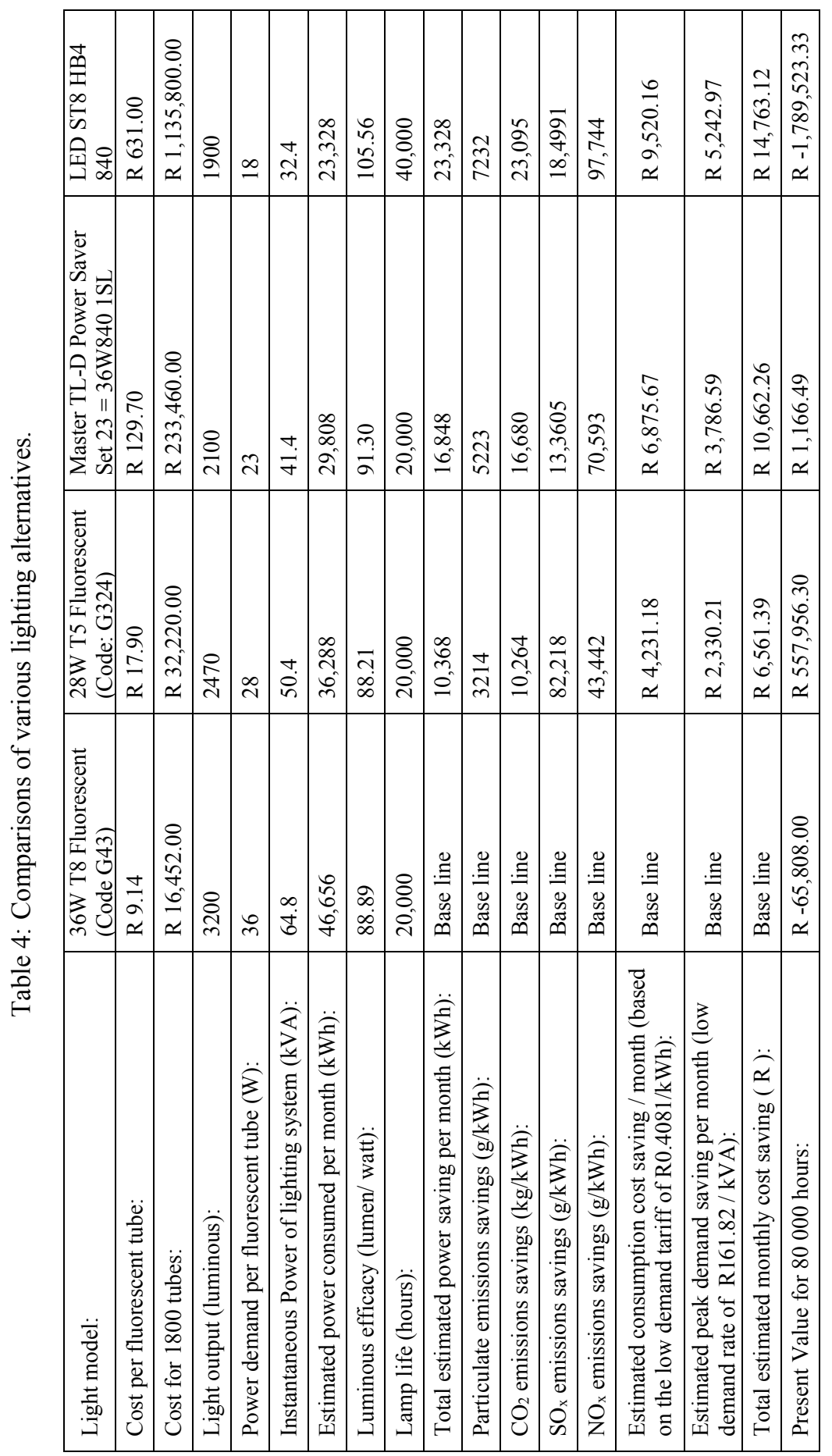




\subsection{Solar initiatives}

From the site visits to the Salt River depot it was established that PRASA's Metrorail maintenance facility was constructed from East to West, thus having a North-South facing roof setup. It was also established that the roof area was fairly substantial, which was further investigated by google earth. Based on these findings it was decided to pursue the viability of installing solar panels as an energy alternative to the grid power currently in use.

\subsubsection{Basic considerations}

Based on discussions Professor A. Brent, from Stellenbosch's Centre for Renewable and Sustainable Energy Studies (CRSES) the various options for roof top solar installations were considered [8]. Currently there exists no policy for private users to feed electricity back into the South African national grid. This means that any excess energy needs to be stored onsite or that the solar system's capacity needs to be limited to not exceed demand. Currently the Salt River maintenance depot runs one day shift, with its peak energy demand coinciding with the peak capacity of any potential solar system. The complexity and cost of onsite energy storage caused the focus of the solar initiative to be on an augmentative solar system.

In order to establish the maximum available solar capacity of the facility, the following aspects had to be taken into account:

- Available roof area.

- Direction of the roof.

- Inclination of the roof.

- Type of solar panel.

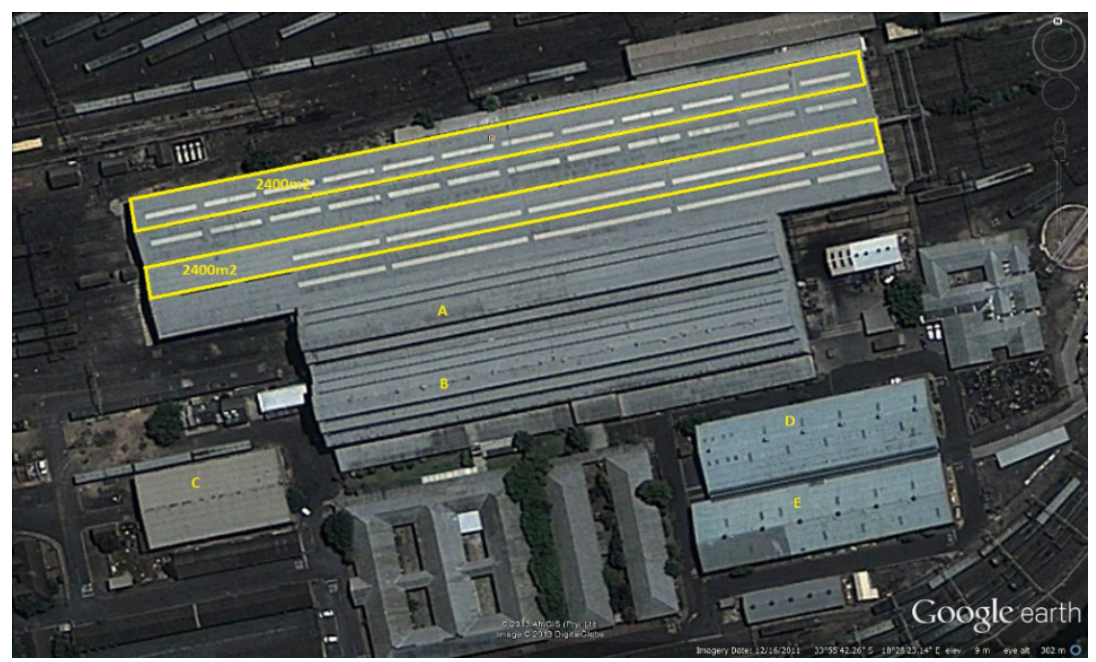

Figure 2: Estimated roof area using Google Earth. 
The Salt River facility has various roof areas, with two sets of roofs facing north. Unfortunately the shorter set of roofs (A and B) are stepped, making them more difficult to use for solar panel installation. The longer set of roofs are uniform. Using google earth any facilities roof area can be quickly calculated to get a general idea, in this case approximately $2400 \mathrm{~m}^{2}$ per north facing section. Based the technical drawings the inclination and exact dimensions can be established. The roof is $240 \mathrm{~m}$ long with a width of $7874 \mathrm{~m}$, with a real roof area $1890 \mathrm{~m}^{2}$. From the technical drawings the inclination of the roof can also be calculated as 22.62 degrees.

From discussions with industry as well as experts at the Stellenbosch University it was decided to select the SPR 320W-E19 Series solar panel for the feasibility study. These panels consist of 96 mono-crystalline solar cells, with a conversion efficiency of 19.5\%. Each panel's dimensions are $1559 \mathrm{~mm} \times 1046 \mathrm{~mm}$ $\mathrm{x} 46 \mathrm{~mm}$, with the minimum spacing between each panel of $10 \mathrm{~cm}$. The maximum number of rows of panels that could be fitted was $4(4 \times 1559 \mathrm{~mm}=6236 \mathrm{~mm})$ compared to the roof side width of $7874 \mathrm{~mm}$. The number of columns was calculated to be $209[240,000 \mathrm{~mm} /(1046 \mathrm{~mm}+100 \mathrm{~mm})=209]$. This results in 836 panels per roof area, and a total of 1672 panels (836 panels $x 2$ sides) for the largest two roofs of the facility.

\subsubsection{Possible annual energy production}

With an installation of 1672 panels, the theoretical maximum power output is calculated as $535.04 \mathrm{kWp}(1672$ x 320W). Using Solar GIS PV Planner [10] a potential yield assessments of photovoltaic power plant could be determined. The geographic position had to be determined, and relevant inputs (system availability, installed power, types of modules, and inclination) had to be entered. The following inputs were used

- Assumed system availability: $\quad 100 \%$

- installed power:

- Type of module:

- Roof inclination:

$535.04 \mathrm{kWp}$

crystalline silicon

$23^{\circ}$

Based on these inputs, PV Planner generated report indicated a possible annual generation 898.7 MWh (or $898700 \mathrm{kWh}$ ).

\subsubsection{Present worth and breakeven analysis}

Due to high initial costs of solar systems, it is important to consider the time value of money (in terms of energy savings), and not just the physical reduction of the monthly utility/ electricity bill. The estimated inflows (monetary value of electricity savings) and outflows (costs) of money should be taken into account for verifying the feasibility of a solar system, as well as other factors such as interest rates, and the number of expected periods/ years of the solar system's operational use. For this case study, it will be assumed that a single once-off payment will be made, and that compounded interest will be of relevance. No subsidies were taken into account due to current difficulties for a rebate allocation in South Africa. 
Industry was asked to quote for a $535.04 \mathrm{kWp}$ system. With an approximate cost of $\mathrm{R} 17,000$ per $\mathrm{kWp}$, this amounts to system cost of approximately R9 095,680.00. This includes all the components as well as installation costs. This quoted cost was used in determining the system's net present worth, as well as the company's breakeven point; the point at which expenses and revenue are equal, taking into account the time value of money. In this case, revenue will be seen as the amount of money saved per year assuming a cost of $40.81 \mathrm{c} / \mathrm{kWh}$ for the first year. It will also be assumed that the company will pay the system completely off at time 0 , without lending money from the bank. Other assumptions made, includes: interest rate of 5\% (i), rate of electrical cost change per year of $8 \%(\mathrm{~g})$, the system's expected operational duration being 25 years (n), and yearly energy production remaining the same.

$$
\begin{gathered}
P=\text { Initial cost }+A 1\left[\frac{1-\left(\frac{1+g}{1+i}\right)^{n}}{i-g}\right]^{n} g \neq i \\
=-9095680+(898700 \times 0.4081)\left[\frac{1-\left(\frac{1+0.08}{1+0.05}\right)^{25}}{0.05-0.08}\right] \\
=+\mathrm{R} 3403161.30
\end{gathered}
$$

Since the calculated present worth at the used interest rate is greater than 0 , this alternative, of installing a solar system of $1672 \times 320 \mathrm{~W}$ PV modules, is proven to be financially viable. However, this was calculated by using an approximate costing factor for each $\mathrm{kWp}$ installed (obtained from one source). It is important to note that no annual maintenance costs were included in these calculations, as one of the significant advantages of solar systems is the low maintenance.

To determine the breakeven point, the amount of years (n) needs to be calculated. Since the breakeven point is where the expenses and revenues are equal, Equation (2) was again used, with the difference that the present worth is equal to zero and solving for $n$ :

$$
\begin{gathered}
0=\text { Initial cost }+A 1\left[\frac{1-\left(\frac{1+g}{1+i}\right)^{n}}{i-g}\right] g \neq i \\
0=-9095680+366759\left[\frac{1-\left(\frac{1+0.08}{1+0.05}\right)^{n}}{0.05-0.08}\right] \\
n=19.74 \text { years }
\end{gathered}
$$




\section{Conclusions and recommendations}

The purpose of this study was to verify whether it is economically feasible to implement the proposed TSE reducing energy management methods. These methods were specifically applied to reduce the full life cycle emissions of the rail facilities. In the case study one example of reducing the energy consumption and one example of changing the energy source, both resulting in a decrease in emissions, were investigated for economic viability.

The lighting system investigation showed that lowering the light output, while still meeting regulatory requirements, by installing lower power fluorescent tubes is feasible. It was also concluded that, although LED replacement tubes are more effective at converting energy into light than fluorescent tubes, the fixed cost of the actual lights makes LED replacement tubes financially infeasible. LED replacement tubes will only become competitive if their fixed cost is more than halved. However, it is expected that LED replacement tube fixed costs will decrease over time and thus should be regularly investigated as an alternative.

Although the buyback or breakeven point of the solar initiative investigation is a significant period it has been shown to be financially viable, with a significant energy saving and thus emission reduction.

From the literature and the case study it is evident that potential energy savings, thus also the emissions reduction potential, and the finical feasibility are extremely dependent on the circumstances. The most significant circumstances being the energy mix available as well as the fixed costs. Any application of the recommended methodologies thus needs to be done carefully on a case by case basis.

Despite the circumstantial sensitivity it has been proven that proposed methodologies are valid and can be applied in general. They will reduce the energy demand of rail facilities and thus the TSE, while being financially feasible.

\section{References}

[1] Climate Change Fact Sheet, Eskom 2012 Financial Results, http:/financialresults.co.za/2012/eskom_ar2012/fact-sheets/006.php\# carbon.

[2] Benefits of Using Energy Saving Lights, ENVISOL, http://www.envisol.co.za/. Date retrieved: 18 May 2013.

[3] Lakatos, L., Hevessy, G. \& Kovács, J., Advantages and disadvantages of solar energy and wind-power utilization, World Futures: Journal of General Evolution, 67(6), pp. 395-408, 2011.

[4] Hermerschmidt, F., Pouloupatis, P.D., Partasides, G., Lizides, A., Hadjiyiannakou, S. \& Choulis, S.A., Beyond solar radiation management - the strategic role of low-cost photovoltaics in solar energy production, International Journal of Sustainable Energy, pp. 1-10, 2013.

[5] Average weather and climate in South Africa, Weather and Climate South Africa website: http://www.weather-and-climate.com/averagemonthlyRainfall-Temperature-Sunshine-in-South-Africa. 
[6] PRASA Utility Bill, City of Cape Town Municipality, 15/3/2013.

[7] Environmental Regulations for Workplaces. Section 35 of the Machinery and Occupational Safety Act, Occupational Health and Safety Act. 1993. South Africa.

[8] Brent, A. Personal communication, 13 August 2013, Former Associate Director, Centre For Renewable and Sustainable Energy Studies, Stellenbosch University, Stellenbosch, South Africa.

[9] Google earth, Image 2014 AfriGIS, www.google.com/earth.

[10] Solar GIS PV planner, Solar GIS Website, http://solargis.info/pvplanner/. 